(2) Open Access Full Text Article

REVIEW

\title{
New and emerging therapies for the treatment of rheumatoid arthritis
}

This article was published in the following Dove Press journal:

Open Access Rheumatology: Research and Reviews

24 July 2010

Number of times this article has been viewed

\author{
Michael G Feely \\ Division of Rheumatology and \\ Immunology, Department of Internal \\ Medicine, University of Nebraska \\ Medical Center, Nebraska Medical \\ Center, Omaha, NE, USA
}

\begin{abstract}
The introduction of tumor necrosis factor (TNF) inhibitors in the late 1990s significantly changed the therapeutic approach for rheumatoid arthritis (RA). With the approval of subsequent TNF inhibitors as well as other biologic agents effective in the management of RA, the treatment paradigm has become increasingly complex. This review examines the current literature regarding the efficacy and toxicity of these and other new anti-rheumatic therapies and discusses effective therapeutic strategies for their use.
\end{abstract}

Keywords: biologics, tumor necrosis factor inhibitors, DMARDs, infliximab, etancercept, adalimumab, golimumab, certolizumab, abatacept, rituximab, tocilizumab

\section{Introduction}

Rheumatoid arthritis (RA) is a systemic autoimmune disorder that primarily targets the synovium of diarthrodial joints. Unchecked synovial inflammation may lead to erosions of periarticular surfaces and juxta-articular osteopenia. It affects approximately $0.8 \%$ of adults and is a cause of significant morbidity and mortality. ${ }^{1}$ Although the cause of RA is incompletely understood, improvements in the understanding of its pathogenesis have occurred over the past few decades. These improvements have contributed to the development of new, potent, biologic medications for management of RA. In addition to the advent of new biologic disease modifying agents, several studies have also demonstrated that goal-oriented treatment strategies with frequent assessments of disease activity are also highly effective. ${ }^{2,3}$ The treatment goals for RA have shifted from primarily symptomatic relief to reducing or eliminating disease activity and altering the progression of the disease, thus improving long-term outcomes and reducing morbidity. Despite the improvements in the understanding of the pathogenesis and treatment of RA, many patients still are unable to achieve remission (or even low disease activity) with currently available medications. Although the pathogenesis of RA is incompletely understood, pro-inflammatory cytokines such as IL-1, IL-6, and tumor necrosis factors (TNFs) have been shown to play an integral role. The development of biologic agents which target these specific inflammatory mediators have provided potent therapies for RA. However, these therapies are much more costly than conventional disease modifying anti-rheumatic drugs (DMARDs), require subcutaneous or intravenous administration, and have toxicities - some of which are not yet fully understood, owing to the lack of long-term experience with these agents. This review will focus on current therapies of RA, including newly developed anti-rheumatic agents as well as therapeutic strategies for achieving control of the manifestations of RA.
Correspondence: Michael G Feely Division of Rheumatology and Immunology, Department of Internal Medicine, University of Nebraska Medical Center, 983025 Nebraska Medical Center, Omaha, NE 68198-3025, USA Email mfeely@unmc.edu 


\section{TNF inhibitors}

TNF is a pro-inflammatory cytokine produced by activated monocytes that is upregulated in the synovium in active RA. It contributes to the synovial inflammation and joint destruction characteristic of RA through activation of proteolytic enzymes, matrix metalloproteinases (MMPs), protein kinases, transcription factors, and enhancement of leukocyte migration. Inhibition of TNF has been associated with improvement in the clinical manifestations of RA as well as reducing radiographic progression. Currently, there are 5 biologic agents targeting the pro-inflammatory cytokine TNF which are approved for the treatment of RA: infliximab (INF), etanercept (ETN), adalimumab (ADA), golimumab (GLM), and certolizumab (CMZ).

INF, the first available TNF inhibitor, was approved for the treatment of RA by the US Food and Drug Administration (FDA) in 1998. It is a chimeric monoclonal antibody to TNF and is given as an intravenous infusion at $3-10 \mathrm{mg} / \mathrm{kg} 2$ and 6 weeks after the initial infusion and every 8 weeks thereafter. Concomitant MTX may reduce the immunogenicity of INF, which has been proposed as a contributing factor to secondary loss of effect. ${ }^{4,5}$ In a randomized, placebo controlled, doubleblind trial of RA patients with active disease despite MTX, INF has been shown to be superior to placebo in achieving clinical response, improving quality of life (QOL) and functional measures and retarding radiographic progression in several randomized double-blind clinical trials. ${ }^{6-8}$ ETN, a soluble dimer of the $\mathrm{p} 75 \mathrm{TNF}$ receptor bound to an Fc portion of IgG1, functions via prevention of TNF from binding to cell-bound TNF receptors. ETN also has the ability to neutralize lymphotoxin (a pro-inflammatory cytokine that binds to the p55 and p 75 TNF receptors) - a property that distinguishes it from the other TNF inhibitors. ETN is administered as a subcutaneous injection ( $25 \mathrm{mg}$ twice per week or $50 \mathrm{mg}$ once per week) and in methotrexate suboptimal responders has been shown to be superior to placebo in achieving rapid improvement in disease activity, improvements in QOL and functional status, and preventing radiographic progression. ${ }^{9-12}$ As with INF, using ETN in combination with MTX results in superior radiographic outcomes than with ETN monotherapy. ${ }^{12}$ ADA is a fully humanized monoclonal antibody to TNF that is given as a subcutaneous injection at a dose of $40 \mathrm{mg}$ every 2 weeks. Similar to the results of other clinical trials of TNF inhibitors, ADA in combination with MTX has been shown to be superior to monotherapy with either drug and has been associated with improvements in QOL indices. ${ }^{13,14}$

GLM is a fully humanized monoclonal antibody to TNF that was approved for RA in 2009. It is administered as a subcutaneous injection at a dose of $100 \mathrm{mg}$ every 4 weeks.
GLM has been shown to be superior to placebo in both MTX naïve patients and those with a suboptimal response to MTX, in achieving ACR 20 responses and DAS 28 defined remission. ${ }^{15-17}$ In patients with active disease despite treatment with TNF inhibitors, significantly more GLM treated patients achieved ACR 20 responses and DAS-defined remission compared with those in the placebo group. ${ }^{18}$

CMZ is a fully humanized monoclonal antibody to TNF, which has been bound to 2 molecules of polyethylene glycol (PEG) which serves to increase pharmacologic half-life and may result in preferential distribution of the drug into inflamed tissues. Also differentiating it from the other TNF inhibitors is the absence of an Fc portion, which results in the inability to form immune complexes with TNF, and thus does not activate complement-dependent cell lysis or antibody-dependent cytotoxicity. CMZ also is not capable of killing cells with membrane bound TNF. CMZ pegol has been shown to have similar efficacy in achieving ACR disease activity measures as the other TNF inhibitors and similarly inhibits radiographic progression. ${ }^{19,20}$ It is given as a subcutaneous injection at a maintenance dose of $200 \mathrm{mg}$ every 2 weeks or $400 \mathrm{mg}$ every 4 weeks following a loading regimen. Monotherapy with CMZ has been shown to be effective although to a slightly lesser extent than when used in combination with MTX. ${ }^{19}$

Despite the documented efficacy of TNF inhibition, a substantial number of patients fail to reach remission or lowdisease activity with these medications. Whether switching to another TNF inhibitor or choosing an agent with a different mode of action is most appropriate in incomplete responders is not clear. Switching from a chimeric to a fully humanized monoclonal antibody has been shown to be effective in improving control of disease activity in many patients, as has switching from a monoclonal antibody to a fusion protein. ${ }^{21,22}$ Registry data has shown that $73 \%$ of patients switching TNF inhibitors remained on the second TNF inhibitor at a mean follow-up of 6 months. ${ }^{23}$ Data from the same registry suggests that that failure of $2 \mathrm{TNF}$ inhibitors is predictive of failure of a third TNF inhibitor. The reason for discontinuation of a second TNF inhibitor is usually the same as that of the first. From the data available, many patients do obtain benefit from switching to another TNF inhibitor, but there is also evidence that escalating therapy to either rituximab (RTX) or abatacept (ABT) is efficacious. If a second TNF inhibitor fails to adequately control disease activity, most would advocate switching to an agent with a different mechanism of action.

TNF inhibitors are largely well tolerated, though they are associated with a unique side-effect profile. The data regarding the increased risk of infection associated with 
TNF inhibition is conflicting. A meta-analysis of randomized clinical control trials of RA patients treated with monoclonal anti-TNF antibodies demonstrated an increased risk of infection (RR 2.0) relative to placebo. ${ }^{24}$ Conversely, longitudinal biologic registries have not shown an overall increased risk of infection with TNF inhibition. However, there does seem to be a period of increased susceptibility to infection within the first 3-6 months of anti-TNF therapy. ${ }^{25}$ The risk of reactivation of latent tuberculosis (TB) is well described with the use of TNF inhibitors, and this signal from early trial data has lead to screening for latent TB prior to initiation of these agents - a practice which has reduced the incidence of reactivation of TB substantially. Registry data of patients receiving TNF inhibitors for RA has shown that the risk of TB differed among the agents, with the risk for the monoclonal antibodies being 3-4 times that of ETN. Overall, the occurrence of TB while on TNF inhibitors is a very rare event, as the BSRBR registry identified 40 cases in 35,000 patient-years of exposure to TNF inhibitors. Interestingly, the risk remains elevated even after the drug is discontinued. Recently, the US FDA released a statement highlighting the need to maintain a high level of suspicion for opportunistic fungal infections, including histoplasmosis, coccidiomycosis, blastomycosis, and others, in patients treated with TNF inhibition. ${ }^{26}$

Significant speculation has occurred regarding a possible association of TNF inhibitors and malignancies specifically lymphomas. A post-marketing report by the US FDA described 26 cases of lymphomas that had occurred in the context of TNF inhibition. ${ }^{27}$ Observational studies have demonstrated an increased incidence of lymphoproliferative disorders (primarily non-Hodgkins lymphoma and Hodgkin's disease) in RA patients, and the risk of lymphomas seems to correlate with disease activity. ${ }^{28,29}$ A large meta-analysis of randomized clinical trials evaluating the treatment of RA with monoclonal anti-TNF antibodies described an increased incidence of malignancy in those receiving TNF inhibition (RR 3.3) relative to placebo. ${ }^{24}$ Notably, there were 9 lymphomas in patients receiving TNF inhibitors compared with none in the placebo arms. However, large observation studies have not shown a significant association of TNF inhibition (ADA, ETN, and INF) with lymphoma and suggest that lymphoma risk is primarily associated with higher levels of disease activity. ${ }^{29}$

Tumor necrosis inhibitors have proven to be quite effective in the management of RA. To date, there is no compelling data to suggest differential efficacies amongst this class of drugs. However, subtle differences in these agents may make one TNF inhibitor favorable over the others in select patients. For example, in patients at high risk for TB or other mycobacterial diseases, ETN is often felt to be more suitable given the slightly lower incidence of TB reported in clinical trials. Conversely, there are select patients in whom the monoclonal antibodies may be a more appropriate choice, such as those with scleritis. Patient preference regarding route and frequency of administration also play a role in the selection of a TNF inhibitor. The TNF inhibitors have not demonstrated terratogenic effects in animal studies and are FDA category $\mathrm{B}$ for pregnancy. Recently, an increased prevalence of congenital anomalies, specifically those within the VACTERL (vertebral, anal atresia, cardiac defects, tracheoesophageal, renal, and limb abnormalities) syndrome, has been described in women treated with TNF inhibitors (ETN and INF) during pregnancy. ${ }^{30}$ This observation prompted the authors to conclude that TNF inhibitors should not be given during pregnancy. Demyelinating diseases have been described in the setting of TNF inhibition, though currently a causal relationship cannot be established. ${ }^{31}$ Treatment with TNF inhibitors is contraindicated in patients with acute hepatitis B and New York Heart Association (NYHA) Class III and IV congestive heart failure. ${ }^{32}$

The TNF inhibitors (and biologics in general) are much more costly than conventional DMARDs. The annual cost for the treatment of RA with TNF inhibition was US\$20,000. ${ }^{33}$ However, due to the efficacy of the medications it has been proposed that their use early in the disease course may prevent the long-term morbidity of RA, and the costs therein (joint replacement surgeries, coronary revascularization, etc). A cost-effective analysis of the treatment of early RA compared 3 different treatment strategies: symptom control with DMARDs added at 1 year for active disease (pyramid strategy), early DMARDs, and early TNF inhibition (with MTX). This analysis clearly showed that early use of conventional DMARDs is economically cost-effective; the same conclusion could not be made for initial TNF inhibition. ${ }^{34}$ An observational study of RA patients demonstrated improvements in disease activity and increased work-force participation over a 5 year period in those treated with TNF inhibitors. ${ }^{35}$ The increase in capacity to work may offer a cost-benefit to the patient or society or at least offset some of the costs associated with therapy. The direct expenses associated with TNF inhibition are significant; however, the indirect costs are difficult to estimate given the limited long-term experience with the agents.

\section{B-cell depletion}

The precise role of B-cells in the pathogenesis of RA is not well understood, though evidence that they contribute significantly to the manifestations of RA is accumulating. 
Both mature B-cells and pre-B-cells express the CD-20 cell surface antigen. RTX has been used effectively in the management of non-Hodgkin's lymphoma since the late 1990s. RTX gained approval for the management of RA in 2006 after being shown to effectively reduce the clinical manifestations of RA. ${ }^{36}$ This trial investigated the efficacy of RTX, with or without cyclophosphamide, relative to placebo in a cohort of RA patients characterized by high disease activity at entry and seropositivity for rheumatoid factor. A statistically significant greater number of RTX-treated patients achieved the primary outcome of an ACR 50 response at 24 weeks when compared with the placebo group. ${ }^{36}$

The REFLEX trial evaluated the efficacy of RTX in patients who had failed at least one TNF inhibitor (with background MTX) and demonstrated the $51 \%$ of patients achieved ACR 20 response by 24 weeks. ${ }^{37}$ Treatment with RTX was shown to be associated with less radiographic progression than was seen in the placebo arm of the REFLEX trial. ${ }^{38}$ The patients receiving RTX in this trial also demonstrated greater improvements in QOL as measured by the FACIT score. ${ }^{37}$ Data from a Swiss cohort of RA patients has shown that switching to RTX after failure of a first TNF inhibitor is associated with a greater reduction in disease activity (DAS 28) when compared with switching to a second TNF inhibitor. ${ }^{39}$

RTX is administered as two infusions of 500-1000 mg 2 weeks apart. Concensus regarding when to re-treat patients does not exist, but is generally not recommended less than 6 months after the initial infusion. The appropriate approach for re-treatment is not well understood. Should RTX be given on a scheduled basis (every 6-12 months) regardless of symptoms, or should re-treatment be initiated when disease activity worsens?

RTX has demonstrated a good safety profile in its use for the management of RA. However, the prolonged depletion of B-cells and immunoglobulins prompts concerns over the risk of infection. However, clinical trial data has not shown significant increases in infection rates despite depletion of B-cells. ${ }^{36}$ Adverse events most commonly occurred during the first infusion, and despite the prolonged effect of B-cell depletion, the infection risk was similar between the placebo and RTX groups at 24 and 48 weeks. ${ }^{36}$ The initiation of other biological therapies following treatment with RTX was not associated with an increased risk of infection despite prolonged peripheral B-cell depletion. ${ }^{40}$ Progressive multifocal leukoencephalopathy (PML) a very rare, but often fatal complication, has been described rarely in RA patients treated with RTX. ${ }^{41}$ RTX therapy is contraindicated in acute viral hepatitis, chronic hepatitis B or C (Child-Pugh class B or C), or in the setting of active infection. ${ }^{42}$

\section{T-cell costimulatory blocking}

ABT is a novel T-cell costimulatory inhibitor which functions through inhibition of the second signal required for T-cell activation. It is a fully humanized soluble fusion protein directed against cytotoxic T-lymphocyte associated antigen-4 (CTLA4). ABT is approved for the treatment of RA and is given as a monthly intravenous infusion of 500-1000 mg (based on weight) after a loading regimen at 0,2 , and 4 weeks.

ABT has been shown effective in reducing the signs and symptoms of RA both in patients with a suboptimal response to MTX or TNF inhibitors. In a double-blind, randomized controlled trial of RA patients with active disease despite MTX monotherapy, ABT (10 mg/kg) was associated with ACR 20 responses of $62.6 \%$ at 1 year, an improvement that was statistically superior to the placebo arm of the trial. ${ }^{43}$ ABT was also associated with higher rates of ACR 50 and 70 responses relative to placebo in this trial. ABT has also been shown to be effective in the management of RA refractory to TNF inhibition. In a large trial of RA patients with an inadequate response to at least one TNF inhibitor, treatment with ABT was associated with ACR 20 responses of $50.4 \%$, a statistically significant higher response than in the placebo group. ${ }^{44}$ ABT has been shown to have a good durability of effect, with efficacy maintained at 5 years in open-label extensions of clinical trials. ${ }^{45}$ Open-label extension of a trial of ABT in MTX non-responders demonstrated that ABT therapy was statistically superior in preventing radiographic progression. ${ }^{46}$ While ABT has proven to be effective both in patients with suboptimal response to MTX as well in those failing TNF inhibitors, questions remain as to what is the best order to use these agents. This question was addressed, in part, by the ATTEST trial, which randomized methotrexate suboptimal responders to receive INF, ABT, or placebo (MTX). Statistically significant reductions in DAS 28 (ESR) were seen in both treatment groups compared with placebo at 6 months and 1 year. Although the trial was not designed to compare the efficacy of ABT and INF, greater reductions in DAS 28 (ESR) were seen in the ABT group $(-2.88$ versus -2.25). The percentage of patients which achieved ACR 50 and 70 responses were also higher with the ABTtreated patients relative to those treated with INF, though the confidence intervals overlapped. ${ }^{47}$ Schiff and colleagues also evaluated the timing of initiation of ABT following an incomplete response to TNF inhibitors. In an open-label trial 
of 1046 patients, no significant differences in efficacies or toxicities were seen regardless of whether patients underwent a 'washout' period ( $\geq 2$ months) or were switched directly, after discontinuation of the TNF inhibitor. ${ }^{48}$

In patients with RA who have failed at least one TNF inhibitor, ABT was associated with improved QOL as measured by improvements in SF-36. ${ }^{49}$ Secondary analysis of the data from the ATTEST trial showed that while patients in both the INF- and ABT-treated groups experienced improvements in health-related QOL indices, the ABTtreated patients had numerically higher mean changes from baseline, in the 8 components of the SF-36, PCS, and MCS, than did the INF-treated patients. ${ }^{47}$

ABT has been shown overall to have a favorable safety profile, with most clinical trials showing no significant increase in adverse events or serious infections when compared with placebo. In the ATTEST trial, the ABT group experienced fewer serious infections than did the INF group, and discontinuations due to serious adverse events were lower in the ABT group compared with the INF group. ${ }^{47}$ Serious infections occurred in $1.9 \%$ of the ABT-treated patients (none of which were opportunistic) compared with $8.5 \%$ in the INF group. Although there are no specific contraindications to the use of ABT, it should be used with caution in chronic obstructive pulmonary disease as it may worsen the lung disease. Initiation of $\mathrm{ABT}$ therapy is not recommended with acute hepatitis $\mathrm{B}$ or $\mathrm{C}$, chronic hepatitis B or C (Child-Pugh class B or C) or in the setting of active infections. ${ }^{42}$ It is recommended that patients be screened for latent TB prior to its use, though no cases of reactivation of $\mathrm{TB}$ have been reported with $\mathrm{ABT}$.

\section{Cytokine inhibition}

Tocilizumab (TCZ) is a fully humanized monoclonal antibody directed against the IL-6 receptor. Interleukin- 6 is a pleiotropic cytokine produced by multiple cell types and has been shown to be implicated in the inflammatory process of RA. Interleukin- 6 is involved in the differentiation of B-cells into plasma cells and T-cells into cytotoxic T-cells, induction of osteoclast differentiation, activation of osteoclasts as well as the production of acute phase reactants, especially C-reactive protein (all of which may contribute to synovitis and bony destruction in RA). Chronic inflammation in RA is associated with increased production of IL- 6 and the IL- 6 receptor. TCZ is currently approved for the management of RA in patients with an incomplete response to TNF inhibition, and is given as a monthly intravenous infusion of $8 \mathrm{mg} / \mathrm{kg}$.

TCZ was associated with reduction in disease activity in 499 RA patients who had failed at least one TNF inhibitor. ${ }^{50}$
This dose-ranging study demonstrated that greater efficacy with a dose of $8 \mathrm{mg} / \mathrm{kg}$. A trial of $359 \mathrm{RA}$ patients with a suboptimal response to MTX, 37\% of those randomized to receive TCZ $(8 \mathrm{mg} / \mathrm{kg})$ achieved ACR 70 responses and the mean DAS 28 of the MTX + TCZ group approached EULAR defined remission (DAS $28<2.6) .^{51}$

TCZ has a side-effect profile unique from the other available biologics. Concerns over a heightened risk of infection with advancing immunosuppression are furthered by a predictable neutropenia occurring following infusion of TCZ. The neutropenia occurs within the first few days following treatment and is postulated to be due (at least in part) to inhibiton of the demarginating effect that IL- 6 has on neutrophils. Data from long-term, open-label extension of TCZ in the management of active RA identified serious infections in $17.5 \%$ of TCZ-treated patients at a rate of 5.7 events per 100 patient-years. Pneumonias were most common, followed by herpes zoster, bronchitis, and pyelonephritis. Febrile neutropenia was not reported, and no patients had withdrawn due to neutropenia. Interestingly, the magnitude and frequency of neutropenia seemed to be less when TCZ was used with background MTX. ${ }^{52}$ Other side-effects of TCZ include elevation of liver function tests (hepatic transaminases and bilirubin) and elevations of total cholesterol, triglycerides, and high-density lipoprotein levels (though the atherogenic index was not markedly changed).

Overall, TCZ demonstrates high retention rates, with 76\% and $66 \%$ of patients remaining on the drug at 3 and 5 years respectively. ${ }^{52}$ In the 5-year follow-up of the STREAM trial, which was characterized by patients with very active disease at enrollment, $22 \%$ of patients withdrew due to adverse events, whereas $0.7 \%$ withdrew due to inefficacy of TCZ. ${ }^{52}$

\section{Small molecules}

Protein kinases are intracellular enzymes that transmit signals via substrate phosphorylation. Once activated, protein kinases express genes leading to transcription proinflammatory cytokines such as TNF, IL-6 and IL-1. As such, these have been evaluated as potential targets for interruption of the inflammatory cascade of RA via suppression of cytokine production. Making this approach even more attractive is that kinase inhibitors can be orally administered and thus offer advantages relative to currently available biologics. Inhibition of 3 protein kinases have been evaluated as treatments for RA - p38 mitogen-activated protein kinase (MAPK), spleen tyrosine kinase (SyK) and Janus kinase (JAK). p38 MAPK is a key regulator of the production of proinflammatory cytokines, and inhibition of these enzymes has been proposed as a 
Table I Currently available biologic therapies for rheumatoid arthritis

\begin{tabular}{|c|c|c|c|}
\hline Drug & Mechanism & Dose/route & Pregnancy class \\
\hline Infliximab & Chimeric monoclonal antibody to TNF & $\begin{array}{l}3-10 \mathrm{mg} \text { at weeks } 0,2 \text {, and } 6 \text { and then } \\
\text { every } 8 \text { weeks; intravenous }\end{array}$ & B \\
\hline Etanercept & Soluble receptor of TNF & $25 \mathrm{mg} 2 \times /$ week or $50 \mathrm{mg} /$ week; subcutaneous & B \\
\hline Adalimumab & Fully humanized monoclonal antibody to TNF & 40 mg every 2 weeks; subcutaneous & B \\
\hline Golimumab & Fully humanized monoclonal antibody to TNF & 100 mg every 4 weeks; subcutaneous & B \\
\hline Certolizumab & $\begin{array}{l}\text { PEGylated fully humanized monoclonal } \\
\text { antibody to TNF }\end{array}$ & $\begin{array}{l}200 \mathrm{mg} \text { every } 2 \text { weeks or } 400 \mathrm{mg} \\
\text { every } 4 \text { weeks; subcutaneous }\end{array}$ & B \\
\hline Abatacept & $\begin{array}{l}\text { Fully humanized fusion protein inhibiting } \\
\text { costimulation of T-cell activation }\end{array}$ & $\begin{array}{l}500-1000 \mathrm{mg} \text { at } 0,2 \text {, and } 4 \text { weeks, then } \\
\text { every } 4 \text { weeks; intravenous }\end{array}$ & $\mathrm{C}$ \\
\hline Rituximab & Chimeric antibody to CD20 cell surface antigen & $1000 \mathrm{mg}$ at 0 and 15 days; intravenous & $\mathrm{C}$ \\
\hline Tocilizumab & $\begin{array}{l}\text { Fully humanized monoclonal } \\
\text { antibody to the IL- } 6 \text { receptor }\end{array}$ & $8 \mathrm{mg} / \mathrm{kg}$ per month; intravenous & $\mathrm{C}$ \\
\hline
\end{tabular}

Abbreviations: TNF, tumor necrosis factor; PEG, polyethylene glycol.

mechanism to interrupt the inflammatory cascade occurring in RA. Despite promising data from animal studies, clinical trials of MAPK inhibition in the management of RA have not shown promising results. ${ }^{53,54}$ When activated, SyK results in increased production of IL-6 and MMPs. Clinical trials of an oral SyK inhibitor (R788) have demonstrated improvements in achieving ACR responses in RA patients with a suboptimal response to methotrexate. ${ }^{55}$ However, Syk inhibition has not been effective in reducing disease activity in RA patients with active disease despite TNF inhibition..$^{56}$ The JAKs play a prominent role in the activation, function, and proliferation of lymphocytes. An oral inhibitor of JAK (CP690 550) has been evaluated in the management of active RA, despite therapy with MTX, ETN, ADA, or INF. Compared with placebo CP690 550 was associated with a rapid, statistical, and clinical improvement in disease activity as measured by an ACR 20 response at 6 weeks..$^{57,58}$ Long-term follow-up and further trials are needed to define the role of protein kinase inhibition in the management of RA.

\section{Goal-oriented approaches}

With expanding availability of highly effective treatments for RA, "remission", (DAS $28<1.6$ ) has become a realistic goal of anti-rheumatic therapies. ${ }^{59}$ In addition to the development of potent biologic medications, several studies (using both conventional DMARDs and biologics) have demonstrated that a goal-oriented approach to therapy is as important as the specific agents selected. ${ }^{2,3}$ The Tight Control in the Treatment of RA (TICORA) trial demonstrated that an intense treatment with frequent assessments and predetermined thresholds for escalation of therapies were nearly 10 times more likely than those treated by "routine care" to achieve clinical remission. ${ }^{2}$ The BeST trial further evaluated the effect of goal-oriented therapies and demonstrated that frequent assessments of disease activity and early escalation to combination therapy (either with conventional DMARDs or INF), $42 \%$ of patients achieved clinical remission (DAS $28<1.6$ ) and $80 \%$ attained an ACR 20 response. Of particular interest in this trial was that a significant number of patients were able to "de-escalate therapy", with successful discontinuation of INF and/or prednisolone following achievement of clinical remission. ${ }^{3}$

\section{Other factors affecting therapies}

With the development of many effective therapies for RA, the treatment paradigm has become ever-complex. While MTX is commonly employed early in the disease course, many patients continue to have active synovitis despite MTX. There is not a well defined consensus paradigm for the treatment of MTX suboptimal responders. All of the approved biologics have been shown to be effective in MTX suboptimal responders, as have combination regimens of conventional DMARDs. The armamentarium of available treatments is expanding, although the order in which these agents should be used remains ill-defined. When presented with an MTX suboptimal responder, several factors affect the choice for subsequent therapies, including cost, comorbid illness(es), and patient preference.

Patient preference for anti-rheumatic therapies is affected by the route of administration, cost, and associated toxicities of the medications. In an analysis of a longitudinal database of RA patients, 35.7 percent of patients reported that they would not want medications administered via subcutaneous injection or infusion. ${ }^{60}$ However, subcutaneous injections have been shown to be preferred by patients over intravenous infusions. ${ }^{61}$ Medication expense affects patient preference for and adherence to therapies. Patients with out-of-pocket medication costs exceeding US\$50 were 58\% more likely to discontinue therapies when compared with those with lower out-of-pocket costs. ${ }^{61}$ Overall, adherence to TNF inhibitor is fairly high, and improves when used in combination 
with conventional DMARDs. ${ }^{62}$ In the analysis performed by Wolfe, a small but statistically significant difference in patient satisfaction with their anti-rheumatic therapies was found, with conventional DMARDs being associated with slightly higher levels of satisfaction. ${ }^{60}$ In this same cohort, nearly three-quarters of patients reported that potential sideeffects of new medications affected their unwillingness to change therapies.

Comorbid illnesses of the patient are important to consider when selecting therapies. Each agent (biologic or conventional) has associated toxicities and side-effects, which may render it a less attractive choice in an individual patient. For example, TNF inhibitors are contraindicated in patients with NYHA Class III or IV heart failure and thus ABT or RTX may be a more suitable choice in these patients. RA often affects women of child bearing age, and thus consideration of terratogenicity and safety during lactation need to be considered when selecting anti-rheumatic therapies.

\section{Other considerations}

In addition to the anti-rheumatic therapies aimed at alleviating synovitis and protecting against erosive changes, the treatment and prevention of comorbid diseases related to RA such as osteoporosis and cardiovascular disease are also important considerations. While the long-term effects of biologic agents of cardiovascular events is not yet fully understood, there is increasing evidence that TNF inhibition may reduce the excess risk of cardiovascular events associated with RA. ${ }^{63}$ Additionally, TNF inhibition has been associated with improvements in endothelial function in patients with RA. ${ }^{64}$ Data regarding the cardiovascular effects of the other biologic agents are lacking currently. A careful review of immunization status and updating immunizations when appropriate is imperative prior to the initiation of biologic therapies. Non-pharmacologic treatments such as physical or occupational therapy, or orthotic, may also be effective adjuncts to pharmacologic therapies.

\section{Conclusion}

The rapid expansion in the number of effective therapies coupled with improved understanding of effective strategies for achieving superior clinical outcomes has revolutionized the treatment of RA. With prompt diagnosis and early treatment and with frequent assessments of disease activity and adjustments in therapy if needed, clinical remission (or at least low disease activity) is attainable in many patients. However, despite the advances in therapies, there is no agent which will effectively achieve remission in all patients, and there are toxicities inherent to all of the anti-rheumatic agents which need to be considered when selecting therapies. There remain many unanswered questions in regards to the order in which these agents should be used. Should early disease be treated aggressively with biologics in combination with conventional DMARDs until remission is achieved and then the biologics discontinued? Or, should biologic agents be reserved for those failing combination DMARDs? At this point, there are no effective biomarkers which predict response to certain therapies in an individual patient. Ultimately, other factors such as patient preference or that of third party payors favoring one route of administration or one agent over another may affect the agent(s) which are selected. As we gain additional experience with these medications and longer follow-up, hopefully some of the unanswered questions as to the timing of treatment/re-treatment, true toxicity profile, and long-term efficacy will be answered.

\section{Disclosure}

The author reports no conflict of interest in this work.

\section{References}

1. Gabriel SE. The epidemiology of rheumatoid arthritis. Rheum Dis Clin North Am. 2001;27(2):269-281.

2. Grigor C, Capell H, Stirling A, et al. Effect of a treatment strategy of tight control for rheumatoid arthritis (the TICORA study): A singleblind randomised controlled trial. Lancet. 2004;364(9430):263-269.

3. Goekoop-Ruiterman YP, de Vries-Bouwstra JK, Allaart CF, et al. Comparison of treatment strategies in early rheumatoid arthritis: a randomized trial. Ann Intern Med. 2007;146(6):406-415.

4. Maini RN, Breedveld FC, Kalden JR, et al. Therapeutic efficacy of multiple intravenous infusions of anti-tumor necrosis factor alpha monoclonal antibody combined with low-dose weekly methotrexate in rheumatoid arthritis. Arthritis Rheum. 1998;41(9):1552-1563.

5. Wolbink GJ, Aarden LA, Dijkmans BA. Dealing with immunogenicity of biologicals: assessment and clinical relevance. Curr Opin Rheumatol. 2009;21(3):211-215.

6. Maini R, St Clair EW, Breedveld F, et al. Infliximab (chimeric antitumour necrosis factor alpha monoclonal antibody) versus placebo in rheumatoid arthritis patients receiving concomitant methotrexate: a randomised phase III trial. ATTRACT study group. Lancet. 1999; 354(9194):1932-1939.

7. Lipsky PE, van der Heijde DM, St Clair EW, et al. Infliximab and methotrexate in the treatment of rheumatoid arthritis. anti-tumor necrosis factor trial in rheumatoid arthritis with concomitant therapy study group. N Engl J Med. 2000;343(22):1594-1602.

8. St Clair EW, van der Heijde DM, Smolen JS, et al. Combination of infliximab and methotrexate therapy for early rheumatoid arthritis: a randomized, controlled trial. Arthritis Rheum. 2004;50(11):3432-3443.

9. Moreland LW, Baumgartner SW, Schiff MH, et al. Treatment of rheumatoid arthritis with a recombinant human tumor necrosis factor receptor (p75)-fc fusion protein. N Engl J Med. 1997;337(3):141-147.

10. Moreland LW, Schiff MH, Baumgartner SW, et al. Etanercept therapy in rheumatoid arthritis. A randomized, controlled trial. Ann Intern Med. 1999;130(6):478-486.

11. Weinblatt ME, Kremer JM, Bankhurst AD, et al. A trial of etanercept, a recombinant tumor necrosis factor receptor:Fc fusion protein, in patients with rheumatoid arthritis receiving methotrexate. $N$ Engl J Med. 1999; 340(4):253-259. 
12. Genovese MC, Bathon JM, Martin RW, et al. Etanercept versus methotrexate in patients with early rheumatoid arthritis: Two-year radiographic and clinical outcomes. Arthritis Rheum. 2002;46(6):1443-1450.

13. Torrance GW, Tugwell P, Amorosi S, Chartash E, Sengupta N. Improvement in health utility among patients with rheumatoid arthritis treated with adalimumab (a human anti-TNF monoclonal antibody) plus methotrexate. Rheumatology (Oxford). 2004;43(6):712-718.

14. Breedveld FC, Weisman MH, Kavanaugh AF, et al. The PREMIER study: A multicenter, randomized, double-blind clinical trial of combination therapy with adalimumab plus methotrexate versus methotrexate alone or adalimumab alone in patients with early, aggressive rheumatoid arthritis who had not had previous methotrexate treatment. Arthritis Rheum. 2006;54(1):26-37.

15. Emery P, Fleischmann RM, Moreland LW, et al. Golimumab, a human anti-tumor necrosis factor alpha monoclonal antibody, injected subcutaneously every four weeks in methotrexate-naive patients with active rheumatoid arthritis: twenty-four-week results of a phase III, multicenter, randomized, double-blind, placebo-controlled study of golimumab before methotrexate as first-line therapy for early-onset rheumatoid arthritis. Arthritis Rheum. 2009;60(8): 2272-2283.

16. Kay J, Matteson EL, Dasgupta B, et al. Golimumab in patients with active rheumatoid arthritis despite treatment with methotrexate: a randomized, double-blind, placebo-controlled, dose-ranging study. Arthritis Rheum. 2008;58(4):964-975.

17. Keystone EC, Genovese MC, Klareskog L, et al. Golimumab, a human antibody to tumour necrosis factor alpha given by monthly subcutaneous injections, in active rheumatoid arthritis despite methotrexate therapy: The GO-FORWARD study. Ann Rheum Dis. 2009;68:789-796.

18. Smolen JS, Kay J, Doyle MK, Landewé R, Matteson EL. Golimumab in patients with active rheumatoid arthritis after treatment with tumor necrosis factor alpha inhibitors (GO-AFTER study): a multicentre, randomised, double-blind, placebo-controlled, phase III trial. Lancet. 2009;374:210-221.

19. Keystone E, Heijde D, Mason D Jr, et al. Certolizumab pegol plus methotrexate is significantly more effective than placebo plus methotrexate in active rheumatoid arthritis: findings of a fifty-two-week, phase III, multicenter, randomized, double-blind, placebo-controlled, parallel-group study. Arthritis Rheum. 2008;58(11):3319-3329.

20. Fleischmann R, Vencovsky J, van Vollenhoven RF, et al. Efficacy and safety of certolizumab pegol monotherapy every 4 weeks in patients with rheumatoid arthritis failing previous disease-modifying antirheumatic therapy: The FAST4WARD study. Ann Rheum Dis. 2009;68(6): 805-811.

21. Buch MH, Bingham SJ, Bryer D, Emery P. Long-term infliximab treatment in rheumatoid arthritis: Subsequent outcome of initial responders. Rheumatology (Oxford). 2007;46(7):1153-1156.

22. Buch MH, Bingham SJ, Bejarano V, et al. Therapy of patients with rheumatoid arthritis: outcome of infliximab failures switched to etanercept. Arthritis Rheum. 2007;57(3):448-453.

23. Hyrich KL, Lunt M, Watson KD, Symmons DPM, Silman AJ. Outcomes after switching from one anti-tumor necrosis factor alpha agent to a second anti-tumor necrosis factor alpha agent in patients with rheumatoid arthritis: Results from a large UK national cohort study. Arthritis Rheum. 2007;56(1):13-20.

24. Bongartz T, Sutton AJ, Sweeting MJ, Buchan I, Matteson EL, Montori V. Anti-TNF antibody therapy in rheumatoid arthritis and the risk of serious infections and malignancies: systematic review and meta-analysis of rare harmful effects in randomized controlled trials. JAMA. 2006;295(19):2275-2285.

25. Dixon WG, Symmons DPM, Lunt M, Watson KD, Hyrich KL, Silman AJ. Serious infection following anti-tumor necrosis factor alpha therapy in patients with rheumatoid arthritis: lessons from interpreting data from observational studies. Arthritis Rheum. 2007;56(9): 2896-2904

26. Food and Drug Administration. FDA: Manufacturers of TNF-blocker drugs must highlight risk of fungal infections. 2008.
27. Brown SL, Greene MH, Gershon SK, Edwards ET, Braun MM. Tumor necrosis factor antagonist therapy and lymphoma development: Twentysix cases reported to the food and drug administration. Arthritis Rheum. 2002;46(12):3151-3158.

28. Gridley G, McLaughlin JK, Ekbom A, et al. Incidence of cancer among patients with rheumatoid arthritis. J Natl Cancer Inst. 1993;85(4): 307-311.

29. Baecklund E, Iliadou A, Askling J, et al. Association of chronic inflammation, not its treatment, with increased lymphoma risk in rheumatoid arthritis. Arthritis Rheum. 2006;54(3):692-701.

30. Carter JD, Ladhani A, Ricca LR, Valeriano J, Vasey FB. A safety assessment of tumor necrosis factor antagonists during pregnancy: A review of the food and drug administration database. $J$ Rheumatol. 2009;36(3):635-641.

31. Magnano MD, Robinson WH, Genovese MC. Demyelination and inhibition of tumor necrosis factor (TNF). Clin Exp Rheumatol. 2004; 22(5):S134-S140.

32. Chung ES, Packer M, Lo KH, Fasanmade AA, Willerson JT. Randomized, double-blind, placebo-controlled, pilot trial of infliximab, a chimeric monoclonal antibody to tumor necrosis factor-alpha, in patients with moderate-to-severe heart failure: results of the anti-TNF therapy against congestive heart failure (ATTACH) trial. Circulation. 2003;107(25):3133-3140

33. Barra L, Pope JE, Payne M. Real-world anti-tumor necrosis factor treatment in rheumatoid arthritis, psoriatic arthritis, and ankylosing spondylitis: cost-effectiveness based on number needed to treat to improve health assessment questionnaire. J Rheumatol. 2009;36(7): 1421-1428.

34. Finckh A, Bansback N, Marra CA, et al. Treatment of very early rheumatoid arthritis with symptomatic therapy, disease-modifying antirheumatic drugs, or biologic agents: a cost-effectiveness analysis. Ann Intern Med. 2009;151(9):612-621.

35. Augustsson J, Neovius M, Cullinane-Carli C, Eksborg S, van Vollenhoven RF. Patients with rheumatoid arthritis treated with tumour necrosis factor antagonists increase their participation in the workforce: Potential for significant long-term indirect cost gains (data from a population-based registry). Ann Rheum Dis. 2010;69(1):126-131.

36. Edwards JC, Szczepanski L, Szechinski J, et al. Efficacy of B-celltargeted therapy with rituximab in patients with rheumatoid arthritis. N Engl J Med. 2004;350(25):2572-2581.

37. Cohen SB, Emery P, Greenwald MW, et al. Rituximab for rheumatoid arthritis refractory to anti-tumor necrosis factor therapy: results of a multicenter, randomized, double-blind, placebo-controlled, phase III trial evaluating primary efficacy and safety at twenty-four weeks. Arthritis Rheum. 2006;54(9):2793-2806.

38. Keystone E, Emery P, Peterfy CG, et al. Rituximab inhibits structural joint damage in patients with rheumatoid arthritis with an inadequate response to tumour necrosis factor inhibitor therapies. Ann Rheum Dis. 2009;68(2):216-221.

39. Finckh A, Ciurea A, Brulhart L, et al. B cell depletion may be more effective than switching to an alternative anti-tumor necrosis factor agent in rheumatoid arthritis patients with inadequate response to anti-tumor necrosis factor agents. Arthritis Rheum. 2007;56(5):1417-1423.

40. Genovese MC, Breedveld FC, Emery P, et al. Safety of biological therapies following rituximab treatment in rheumatoid arthritis patients. Ann Rheum Dis. 2009;68(12):1894-1897.

41. Fleischmann RM. Progressive multifocal leukoencephalopathy following rituximab treatment in a patient with rheumatoid arthritis. Arthritis Rheum. 2009;60(11):3225-3228.

42. Saag KG, Teng GG, Patkar NM, et al. American college of rheumatology 2008 recommendations for the use of nonbiologic and biologic disease-modifying antirheumatic drugs in rheumatoid arthritis. Arthritis Rheum. 2008;59(6):762-784.

43. Kremer JM, Dougados M, Emery P, et al. Treatment of rheumatoid arthritis with the selective costimulation modulator abatacept: twelvemonth results of a phase iib, double-blind, randomized, placebocontrolled trial. Arthritis Rheum. 2005;52(8):2263-2271. 
44. Genovese MC, Becker JC, Schiff M, et al. Abatacept for rheumatoid arthritis refractory to tumor necrosis factor alpha inhibition. N Engl J Med. 2005;353(11):1114-1123.

45. Westhovens R, Kremer JM, Moreland LW, et al. Safety and efficacy of the selective costimulation modulator abatacept in patients with rheumatoid arthritis receiving background methotrexate: a 5-year extended phase IIB study. J Rheumatol. 2009;36(4):736-742.

46. Genant HK, Peterfy CG, Westhovens R, et al. Abatacept inhibits progression of structural damage in rheumatoid arthritis: Results from the long-term extension of the AIM trial. Ann Rheum Dis. 2008;67(8): 1084-1089.

47. Schiff M, Keiserman M, Codding C, et al. Efficacy and safety of abatacept or infliximab vs placebo in ATTEST: a phase III, multicentre, randomised, double-blind, placebo-controlled study in patients with rheumatoid arthritis and an inadequate response to methotrexate. Ann Rheum Dis. 2008;67(8):1096-1103.

48. Schiff M, Pritchard C, Huffstutter JE, et al. The 6-month safety and efficacy of abatacept in patients with rheumatoid arthritis who underwent a washout after anti-tumour necrosis factor therapy or were directly switched to abatacept: The ARRIVE trial. Ann Rheum Dis. 2009;68(11): 1708-1714.

49. Westhovens R, Cole JC, Li T, et al. Improved health-related quality of life for rheumatoid arthritis patients treated with abatacept who have inadequate response to anti-TNF therapy in a double-blind, placebo-controlled, multicentre randomized clinical trial. Rheumatology (Oxford). 2006;45(10):1238-1246.

50. Emery P, Keystone E, Tony HP, et al. IL-6 receptor inhibition with tocilizumab improves treatment outcomes in patients with rheumatoid arthritis refractory to anti-tumour necrosis factor biologicals: Results from a 24-week multicentre randomised placebo-controlled trial. Ann Rheum Dis. 2008;67(11):1516-1523.

51. Maini RN, Taylor PC, Szechinski J, et al. Double-blind randomized controlled clinical trial of the interleukin-6 receptor antagonist, tocilizumab, in European patients with rheumatoid arthritis who had an incomplete response to methotrexate. Arthritis Rheum. 2006;54(9):2817-2829.

52. Nishimoto N, Miyasaka N, Yamamoto K, Kawai S, Takeuchi T, Azuma J. Long-term safety and efficacy of tocilizumab, an anti-IL-6 receptor monoclonal antibody, in monotherapy, in patients with rheumatoid arthritis (the STREAM study): evidence of safety and efficacy in a 5-year extension study. Ann Rheum Dis. 2009;68(10):1580-1584.

53. Cohen SB, Cheng T, Chindalore V, et al. Evaluation of the efficacy and safety of pamapimod, a p38 MAP kinase inhibitor, in a double-blind, methotrexate-controlled study of patients with active rheumatoid arthritis. Arthritis Rheum. 2009;60(2):335-344.
54. Alten RE, Zerbini C, Jeka S, et al. Efficacy and safety of pamapimod in patients with active rheumatoid arthritis receiving stable methotrexate therapy. Ann Rheum Dis. 2010;69(2):364-367.

55. Weinblatt ME, Kavanaugh A, Burgos-Vargas R, et al. Treatment of rheumatoid arthritis with a syk kinase inhibitor: a twelve-week, randomized, placebo-controlled trial. Arthritis Rheum. 2008;58(11):3309-3318.

56. Genovese MC, Kavanaugh A, Peterfy CG, Magilavy D. An oral syk kinase inhibitor in the treatment of rheumatoid arthritis (RA): a 3 month randomized placebo controlled phase 2 study in patients with active RA who had failed biologic agents. ACR 2009. 2009; Late Breaking Abstract 3.

57. Kremer JM, Bloom BJ, Breedveld FC, et al. The safety and efficacy of a JAK inhibitor in patients with active rheumatoid arthritis: Results of a double-blind, placebo-controlled phase IIa trial of three dosage levels of CP-690,550 versus placebo. Arthritis Rheum. 2009;60(7): 1895-1905.

58. Coombs JH, Bloom BJ, Breedveld FC, et al. Improved pain, physical functioning and health status in patients with rheumatoid arthritis treated with CP-690,550, an orally active janus kinase (JAK) inhibitor: Results from a randomised, double-blind, placebo-controlled trial. Ann Rheum Dis. 2010;69(2):413-416.

59. Sokka T, Mäkinen H, Puolakka K, Möttönen T, Hannonen P. Remission as the treatment goal - the FIN-RACo trial. Clin Exp Rheumatol. 2006; 24(6):S74-S76.

60. Wolfe F, Michaud K. Resistance of rheumatoid arthritis patients to changing therapy: discordance between disease activity and patients' treatment choices. Arthritis Rheum. 2007;56(7):2135-2142.

61. Curkendall S, Patel V, Gleeson M, Campbell RS, Zagari M, Dubois R. Compliance with biologic therapies for rheumatoid arthritis: Do patient out-of-pocket payments matter? Arthritis Rheum. 2008;59(10): 1519-1526.

62. Zink A, Listing J, Kary S, et al. Treatment continuation in patients receiving biological agents or conventional DMARD therapy. Ann Rheum Dis. 2005;64(9):1274-1279.

63. Dixon WG, Symmons DPM. What effects might anti-TNFa treatment be expected to have on cardiovascular morbidity in rheumatoid arthritis? A review of the role of $\mathrm{TNFa}$ in cardiovascular pathophysiology. Ann Rheum Dis. 2007;66(1):1132-1136.

64. Ferrante A, Giardina AR, Ciccia F, et al. Long-term anti-tumour necrosis factor therapy reverses the progression of carotid intima-media thickness in female patients with active rheumatoid arthritis. Rheumatol Int Epub 2009 Apr 23.

\section{Publish your work in this journal}

Open Access Rheumatology Research and Reviews is an international, peer-reviewed, open access journal, publishing all aspects of clinical and experimental rheumatology in the clinic and laboratory including the following topics: Pathology, pathophysiology of rheumatological diseases; Investigation, treatment and management of rheumatological

\section{Dovepress}

diseases; Clinical trials and novel pharmacological approaches for the treatment of rheumatological disorders. The manuscript management system is completely online and includes a very quick and fair peerreview system, which is all easy to use. Visit http://www.dovepress.com/ testimonials.php to read real quotes from published authors. 